\title{
Romanceiro da Inconfidência: a construção de uma biografia em falsete
}

Kátia da Costa Bezerra

The University of Arizona

Resumo: O presente ensaio pretende se deter em alguns dos inventários do Romanceiro da Inconfidência, de Cecília Meireles, para discutir a forma como estes elementos contribuem para a formação de um catálogo que problematiza políticas identitárias e de construção da nação.

Palavras-chave: Memória, História, Nação.

\author{
Onde estão seus vastos sonhos, \\ Ó cidade abandonada? \\ De onde vinham? Para onde iam? \\ Por onde foi que passaram? \\ Não deve sonhar o pobre, \\ que o pobre não vale nada... \\ Se o sonho do pobre é crime, \\ quanto mais qualquer palavra!
}

1. MEIRELES. Romanceiro da Inconfidência, p. 251.

2. MEIRELES. Romanceiro da Inconfidência, p. 131. 
Cecília Meireles nasceu na cidade do Rio de Janeiro em 7 de setembro de 1901 e faleceu em 9 de novembro de 1964. Órfã muito cedo, foi criada pela avó materna, Jacinta Garcia Benevides. Cecília foi poeta, cronista, professora, diretora escolar, tradutora, jornalista, produtora de peças teatrais, conferencista e autora de livros infantis e didáticos. Em 1919, aos 18 anos de idade, publicou o seu primeiro livro de poesia, Espectros. Entre junho de 1930 e janeiro de 1933, ela manteve a "Página da Educação" no Diário de Notícias do Rio de Janeiro, onde publicava artigos e entrevistas sobre educação, política e cultura. Cecília participou ativamente do movimento reformista da Escola Nova, que propunha uma política nacional de educação e ensino que possibilitasse a implantação de um ensino laico, universal, obrigatório e centrado no aluno. ${ }^{3}$ Em sua página no Diário de Notícias, Cecília defendia o projeto de reforma e modernização do ensino, criticando veementemente aqueles que pregavam pela volta do ensino religioso às escolas públicas, como era o caso do Sr. Francisco Campos, secretário da Educação do Distrito Federal e posteriormente ministro do governo de Getúlio Vargas. ${ }^{4}$

Seu envolvimento com a proposta de modernização da educação, no entanto, não ficou restrita à sala de aula ou aos embates nos jornais. Em 1934, Cecília e seu marido, o pintor português Fernando Correia Dias, se dedicaram à criação do Centro Cultural Infantil do Pavilhão Mourisco, inaugurado em 1934 no Rio de Janeiro. Tratava-se de um centro de cultura infantil onde as crianças podiam desenvolver atividades artísticas e musicais e frequentar a primeira biblioteca pública infantil no Brasil. A A partir de 1935, com o suicídio do marido, ela teve que arcar sozinha com a responsabilidade financeira de manutenção das três filhas do casal. Isso a obrigou a trabalhar em jornais, retomar a carreira de professora e a direção do Pavilhão Mourisco.

A forma combativa como Cecília Meireles defendia suas ideias pode nos ajudar a compreender o modo como foi perseguida, de maneira mais ou menos velada, durante o governo de Getúlio Vargas. Em suas crônicas nos

3. Cecília Meireles foi uma das 26 intelectuais do Manifesto dos Pioneiros da Educação Nova, lançado em 1932, que defendia, entre outras coisas, a criação de creches, a coeducação entre os sexos, e jardins da infância.

4. LAMEGO. A farpa na lira, p. 101.

5. LOBO. Memória e educação: o espírito victorioso de Cecília Meireles, p. 528. 
jornais, Cecília se recusava a compartilhar do tom ufanista e nacionalista de Vargas, a quem denominava "O Ditador". ${ }^{6}$ Como resultado, em 1937, o Estado Novo fechou o Centro de Cultura Infantil após apreender o livro As aventuras de Tom Sawyer, de Mark Twain, tido como um livro de "conotações comunistas". O debate que precedeu a premiação pela Academia Brasileira de Letras de seu livro de poesia Viagem em 1939 é outro exemplo da forma como suas ideias afetaram sua carreira. A premiação foi marcada por uma tensa disputa entre os membros do comitê, com repercussão na imprensa e na opinião pública da época. Segundo Yolanda Lima Lobo, a tensão se originou da presença, na comissão, de acadêmicos como Fernando de Magalhães, que fora duramente criticado por Cecília por suas propostas pedagógicas. Para culminar, apesar de escolhida para ser a oradora dos contemplados no dia da premiação, diante da intransigência de alguns acadêmicos que teimavam em censurar seu discurso, ela declinou da honra. ${ }^{9}$ Em 1965, um ano após o seu falecimento, a Academia Brasileira de Letras concedeu-lhe o Prêmio Machado de Assis pelo conjunto de sua obra.

Em pesquisa desenvolvida em torno das contribuições de Cecília Meireles para o jornal A Manhã, onde manteve a seção "Professores e Estudantes", de 1941 a 1943, a pesquisadora Luiza Franco Moreira argumenta que o tom combativo dos anos 30 é, aos poucos, substituído por uma flexão mais irônica e menos energética. Moreira aponta a presença de uma nova teologia nas crônicas de Cecília, em que, apesar da presença de um tom crítico, este se esboça de forma mais sutil, sinalizando certo desencanto por parte da poeta. Esse desencanto pode ser explicado, em parte, pela desilusão frente às reformas de ensino implementadas durante o governo Vargas, que não trouxeram as inovações almejadas pelos adeptos da Escola Nova. Como argumenta Arnaldo Niskier, Cecília sempre se posicionou em defesa de uma escola moderna que deveria promover mudanças sociais, oferecendo oportunidades iguais a todos. ${ }^{10}$

6. NISKIER. Cecília Meireles: a educadora, p. 276.

7. LOBO. Memória e educação: o espírito victorioso de Cecília Meireles, p. 537.

8. Essa tensão tem como base a discussão envolvendo as propostas pedagógicas de tese de Cecília Meireles Espírito victorioso quando esta foi preterida no concurso na Escola Normal do Distrito Federal.

9. LOBO. Memória e educação: o espírito victorioso de Cecília Meireles, p. 539-540.

10. NISKIER. Cecília Meireles: a educadora, p. 275. 
Fruto de uma pesquisa que durou quase dez anos e que culminou com a publicação do livro em 1953, o Romanceiro da Inconfidência está impregnado, de certa maneira, por essa nova sensibilidade teológica de que fala Moreira. É a essa faceta crítica que esse ensaio pretende se ater ao examinar o livro Romanceiro da Inconfidência. ${ }^{11}$ Composto de oitenta e cinco romances entremeados por cinco falas, quatro cenários e uma serenata, o Romanceiro procura inserir dramas individuais nos tensos e violentos episódios que vão da descoberta do ouro e de pedras preciosas na região das Gerais à Inconfidência Mineira. Os poemas reproduzem monólogos, diálogos, relatos e conjecturas que visam trazer uma nova dimensão à conjuração. Várias são as estratégias empregadas para questionar uma visão ufanista e unívoca da nação, no intuito de aproximar o relato celebratório dos muitos e muitas vezes esquecidos personagens de seu tempo. Dentre estas, pode-se citar a coexistência de diferentes relatos sobre o enforcamento de Tiradentes, que, em diversos momentos, entram em tensão. Depara-se o leitor, igualmente, com um inventário de pessoas, de aspectos do quotidiano e de paisagens que visam capturar uma multiplicidade que traz um novo colorido para a nação. O presente ensaio pretende se deter em alguns desses inventários para discutir a forma como estes elementos contribuem para a formação de um catálogo que problematiza políticas identitárias que procuram definir a nação. Todavia, antes de se prender mais especificamente à análise da poesia de Cecília Meireles, o ensaio procura discutir a forma como o mito da Inconfidência é construído e retomado em diferentes momentos históricos.

\section{A Inconfidência e a memória: a (des)construção de um mito}

Segundo Eric Hobsbawm, a invenção de uma tradição envolve, entre outras coisas, o desejo de impor uma política particular de seleção e organização que passa a ser considerada como representativa de toda uma comunidade. Essa leitura hegemônica busca legitimar uma memória "comum" que se estrutura a partir de um conjunto de práticas culturais regidas por códigos e rituais de

11. Segundo Valéria Lamego, a Revolução de 30 forçou o intelectual a se envolver em discussões políticas, ou seja, a definir posições ideológicas, como é o caso de Cecília Meireles e sua atuação no âmbito da educação. 
natureza simbólica que passam a dar sentido à nação. A Inconfidência Mineira é uma dessas invenções. Celebrada como um evento patriótico, a Inconfidência Mineira foi uma tentativa de subversão contra a coroa portuguesa em 1789, em função da intensificação do controle fiscal sobre a extração e circulação do ouro. ${ }^{12}$ A construção desse mito remonta ao século XIX, quando, segundo José Murilo de Carvalho, a república recém-criada, vivendo um período de turbulência e de necessidade de afirmação, precisava de um herói que possibilitasse a formação de uma consciência nacional.

Os vários embates em torno da transformação de Tiradentes em um "herói cívico-religioso" nos ajudam a compreender alguns dos dilemas envolvidos na construção da memória oficial. Em seu estudo, Carvalho descreve as várias forças e interesses em disputa na seleção dos prováveis "candidatos". O autor explica que, por um lado, a escolha por Tiradentes decorreu do fato de ser ele uma pessoa do povo e de a Inconfidência não ter sido um movimento separatista nem ter resultado em uma matança indiscriminada. A distância no tempo e a falta de registros precisos, por outro lado, propiciaram um solo fértil para disputas envolvendo os vários grupos políticos da época. Da mesma forma, a ausência de retratos do Alferes permitiu a lenta aproximação de sua imagem à de Jesus Cristo - algo que, como demonstra Carvalho, reforçava a ideia do martírio e do sacrifício, forjando uma analogia que tinha profundas ressonâncias numa sociedade tradicionalmente católica. ${ }^{13}$ A centralidade da figura de Tiradentes também pode ser explicada pela forma como o mito retoma o tema do sacrifício pela pátria. Nesse caso, Tiradentes simboliza o cidadão-soldado de que fala Benedict Anderson, que, acima de tudo, está disposto a matar e, principalmente, morrer pela pátria.

O processo de invenção do mito de Tiradentes, no entanto, vai ganhar novas nuances com o tempo. Isso decorre do fato de que, segundo Maurice Halbwachs, o contínuo processo de reelaboração da memória resulta de mudanças nas agendas políticas e culturais, assim como nos contextos históricos. Por outro lado, como tão bem adverte Jeffrey Olick, "as imagens

\section{MAXWELL. Conflicts and conspiracies, 1973.}

13. As pinturas e esculturas que retratam o enforcamento sempre trazem um Tiradentes com cabelos longos e barba. Segundo os historiadores, era costume na época cortar completamente a barba e o cabelo dos condenados, para que não atrapalhassem no momento do enforcamento. 
do passado não são ditadas nem pelo passado nem totalmente inventadas no presente mas resultam de um contínuo diálogo no qual as imagens anteriores moldam e restringem o que pode ser feito com elas em presentes sucessivos" ${ }^{14}$. Essa constante tensão no redimensionamento do passado pode nos ajudar a compreender o papel fundamental da performance dos valores cívicos em eventos públicos ou da presença de monumentos e museus que, numa relação metonímica, procuram estabelecer e legitimar uma certa relação entre passado, presente e futuro. ${ }^{15}$ Essa tensão permite desnudar os mecanismos envolvidos na utilização política dessa memória coletiva nos momentos em que se torna necessário reestruturar ou manter a ordem social.

Historicamente na América Latina, discursos nacionalistas têm sido empregados como um ponto de convergência para mobilização ou desmobilização política. Nos momentos de crise, intensifica-se a preocupação em organizar cerimônias cívicas ou criar panteões que passam a funcionar como um instrumento vital na formação e manutenção de um sentido de cidadania. A elevação de Ouro Preto a monumento nacional em 1936 e a decisão de transformar a antiga Casa de Câmara e Cadeia de Vila Rica no panteão dos inconfidentes em 1937 apontam para a forma como a história da Inconfidência vem sendo reapropriada pelo poder oficial em momentos de crise. ${ }^{16}$ Em 1942, no aniversário de 150 anos da sentença de condenação dos inconfidentes, o panteão foi inaugurado com a presença de Getúlio Vargas, só sendo aberto completamente ao público em 1944. É interessante observar que, além dos inconfidentes, o panteão também é composto do túmulo de Maria Doroteia Joaquina de Seixas, a musa decantada nas liras de Tomás Antonio Gonzaga, e do

14. "...images of the past are neither dictated by the past nor wholly invented in the present but result from an ongoing dialogue in which earlier images shape and constrain what can be done with them in successive presents". OLICK. What does it mean to normalize the past? Official memory in German politics since 1989, p. 552. (Tradução minha.)

15. ANDERSON. Imagined communities, 1991.

16. Os despojos dos inconfidentes que morreram na África foram transladados para o Brasil. O objetivo de preservar a memória do Brasil Colônia torna-se parte do projeto do IPHAN, órgão recém-criado pelo governo de Getúlio Vargas para preservar os monumentos históricos e artísticos brasileiros. 
cenotáfio de Bárbara Eliodora da Silveira, poeta e esposa do poeta e inconfidente Alvarenga Peixoto ${ }^{17}$.

Para melhor compreender a forma como esse panteão se estrutura é importante lembrar que os anos 30 no Brasil foram um período marcado por profundas transformações e turbulências que culminaram com a implantação da ditadura Vargas em 1937. Uma das estratégias usada por Vargas para dar sustentação à nova ordem foi se apropriar de uma série de mitos que faziam parte do imaginário nacional. A centralidade da Inconfidência Mineira pode ser explicada pelo modo como o mito tem na sua origem o desejo de inspirar o amor incondicional à pátria. O que se observa foi a forma como o mito se tornou um instrumento essencial na formação de um sentido de cidadania que pudesse legitimar o poder político de Vargas, garantindo coesão e ordem. A constante ênfase e conexão que se estabeleceu entre as instituições da família e da nação em vários dos pronunciamentos e na política de Vargas, por outro lado, pode nos ajudar a compreender a inclusão dos monumentos a Bárbara Eliodora e Maria Doroteia Joaquina Seixas no panteão, uma vez que estas são integradas como símbolos de virtude e abnegação. Essa leitura aponta para o caráter gendrado da nação, uma vez que as mulheres ficam restritas ao papel de reprodutoras biológicas, culturais e simbólicas das coletividades nacionais, resultando no seu alijamento, ao menos no nível do simbólico, do processo de construção e transformação da nação, que passa a ser percebido como uma prerrogativa masculina. ${ }^{18}$

O que está em causa na produção de lugares de memória, por conseguinte, é a necessidade de criar e reforçar uma tradição que é percebida como um alicerce fundamental para inspirar e prover um sentido de continuidade e estabilidade para o indivíduo e a nação. Por essa razão, essas "grandes narrativas" são constantemente disseminadas pela mídia, ensinadas nas escolas

17. Muitos outros marcos relacionados com a conjuração vão contribuir para a cristalização desse fato no imaginário da nação. Pode-se citar a escolha da bandeira dos inconfidentes como a bandeira oficial do Estado de Minas Gerais em decreto em 8 de janeiro de 1963. Em 1952, o governador Juscelino Kubitschek criou a Medalha da Inconfidência e Brasília foi fundada no mesmo dia da execução de Tiradentes em 21 de abril de 1960. Mais recentemente, em 1965, o governo militar escolheu Tiradentes como o patrono cívico da nação.

18. YUVAL-DAVIS; ANTHIAS. Introduction, p. 7. 
e integradas na vida diária. Nas escolas, as aulas são organizadas em torno do conteúdo de livros que são reconhecidos como a versão legitimada do conhecimento. ${ }^{19}$ Estabelece-se, assim, a conexão entre as escolas, para citar um caso, e o processo de reprodução da ordem social. Como Raymond Williams afirma, ao definir o que deve ser ensinado nas escolas, os livros escolares reforçam aqueles aspectos que devem ser vistos como parte de uma tradição. O problema com a imposição de uma determinada leitura é que, como afirma Lawrence J. Kirmayer:

Esses modelos culturais influenciam o que é visto como saliente, como é interpretado e codificado no momento do registro e, mais importante para memórias de longo tempo que servem funções autobiográficas, o que é socialmente possível falar e o que deve permanecer escondido ou sem reconhecimento. ${ }^{21}$

É essa "biografia" da nação que o Romanceiro da Inconfidência procura colocar em questionamento ao evidenciar tradições/experiências suprimidas, ou seja, reconstruir perspectivas e experiências diferentes daquelas disponíveis e reconhecidas como "representativas". Muitas vezes, isso implica a presença de uma escrita que se estrutura a partir de uma repetição em falsete que, ao modificar o original, revela suas fissuras e suas contradições. ${ }^{22}$ Trata-se de uma forma de escrita que exige uma dupla postura por parte do leitor: uma leitura evocativa do modelo original e outra que se afasta desse modelo, em função da inserção de outras perspectivas/leituras. Desta maneira, a nação surge como um espaço tenso, fraturado e múltiplo, afastando-se, consequentemente, das formulações nacionalistas fundadas em valores universais como o progresso; desmascarando, assim, a falsa objetividade e autoridade das metanarrativas.

19. APPLE. Teachers and texts. a political economy of class and gender relations in education, p. 86.

20. WILLIAMS. Hegemony and the selective tradition, p. 59-60.

21. "Such cultural models influence what is viewed as salient, how it is interpreted and encoded at the time of the registration and, most important for long-term memories that serve autobiographical functions, what is socially possible to speak of and what must remain hidden and unacknowledged." KIRMAYER. Landscapes of memory: Trauma, narrative, and dissociation, p. 191. (Tradução minha.)

22. DELEUZE. Difference and repetition, p. 1-2. 
No caso do Romanceiro, o que se percebe é o afloramento de uma polifonia de atores, construindo uma história que não fica restrita à fala dos personagens principais. Na realidade, embora o Alferes Tiradentes ocupe o espaço central nessa nova encenação do passado, os poemas mesclam os relatos dos inconfidentes e dos governantes com a fala de uma infinidade de atores como tropeiros, ciganos, mulheres, caixeiros e bêbados. Da mesma forma, a cidade, os montes e os cavalos se apresentam como testemunhas de um tempo de sonho, traição, corrupção, medo e sofrimento. Como adverte a poeta em palestra proferida em Ouro Preto em 1955, o Romanceiro se detém em um jogo de poder e violência que "durou cem anos [...] seguindo o rastro do ouro ligando personagens e cenas”. De fato, o desejo de situar a Inconfidência num crescendo de cobiça, traição, violência e revolta faz com que o Romanceiro se refira a eventos anteriores à Inconfidência como o da destruição do Arraial de Ouro Podre ou a história de Chica da Silva, por exemplo.

Em seu estudo da obra, Leopoldo Bernucci argumenta que o Romanceiro procura questionar "a autoridade da história ao impregná-la com uma ironia poderosa que desvela as várias distorções e contradições dos episódios”. ${ }^{24}$ Eu diria que esse processo de deslocamento e reescrita se estrutura a partir de uma infinidade de estratégias como a mescla de dados oriundos de documentos oficiais a histórias que fazem parte do folclore popular. A inserção de diferentes perspectivas, como no caso do enforcamento de Tiradentes, também funciona como uma estratégia que visa questionar leituras totalizantes. Da mesma forma, a multiplicidade de significados assumidos por termos como "loucura" visa levar o leitor a refletir sobre o papel da linguagem na forma como a história é

23. O poema se refere ao conhecido Morro da Queimada. O Arraial do Ouro Podre foi um dos primeiros a surgir em Ouro Preto e foi destruído em 1720 por causa da revolta ocasionada pela oposição a certas medidas da Coroa Portuguesa, como a criação de casas de fundição e a proibição de circulação do ouro em pó. Após 18 dias de cerco ao palácio do governo, foi decretada uma trégua em que o governador se comprometeu a perdoar os revoltosos e aceitar suas imposições. Tão logo os revoltosos retornaram para suas propriedades no Morro da Queimada, o conde de Assumar incendiou o local. Felipe dos Santos, que tinha conseguido fugir, foi preso, enforcado e depois amarrado à cauda de um cavalo que arrastou seu corpo.

24. "...the authority of history by charging it with a powerful irony that displays the many twists and contradictions of the episodes". BERNUCCI. That gentle epic: Writing and elegy in the heroic poetry of Cecília Meireles, p. 205. (Tradução minha.) 
narrada. ${ }^{25}$ Em qualquer desses momentos, no entanto, mais do que a instabilidade do signo, o que chama a atenção é a forma como o Romanceiro questiona o conceito de neutralidade da história, propiciando um espaço de problematização do próprio ato de narrar.

Para corroborar esse fato é importante lembrar que o Romanceiro não só alude às histórias ouvidas, mas também àquelas que só podem ser adivinhadas, como adverte a voz poética. O propósito de completar os espaços em branco que as narrativas oficiais deixaram faz com que a conjuração perca sua aura romântica e idealizada, sendo enquadrada a partir de marcos que realçam a forma como "a febre do ouro e o sonho de liberdade" afetaram de forma diferente os vários indivíduos. Consciente das discrepâncias entre discursos que apregoam uma imagem do Brasil marcado pela tolerância e cordialidade de que falaria mais tarde Marilena Chauí, o Romanceiro recupera aspectos de um quotidiano normalmente esquecido no processo de construção do mito, como se verá a seguir.

\section{O silêncio e a invisibilidade dos relatos oficiais}

É indubitável que reescrever os eventos históricos a partir de quadros mais abrangentes oferece ao leitor a possibilidade de examinar os mecanismos responsáveis pela legitimação de ideias, valores e práticas que tentam estruturar a vida em sociedade. Por essa razão, ao contrário dos relatos oficiais, o Romanceiro é povoado por uma diversidade de atores usualmente ausentes do cenário da nação, como se pode perceber no "Romance XXI ou Das Idéias". ${ }^{26}$ Poema em redondilha maior, composto de seis estrofes irregulares, seus versos descrevem várias facetas da vida em Vila Rica, conjugando os espaços dos campos e das cidades com um universo impregnado pela arte barroca, diversos modos de viver e a poesia árcade. A quebra de uma aparente harmonia na descrição da vila surge pela presença do verso "E as idéias" que funciona como um estribilho fechando as estrofes. Composto de três sílabas, o verso rompe com a estrutura

25. O termo "loucura" aparece associado à ideia da cobiça pelo ouro e pedras preciosas, ao remorso de D. Maria I, à fala destemida do sonho de liberdade (o Alferes) ou a um espaço de fuga para a dor (Dona Bárbara Eliodora).

26. MEIRELES. Romanceiro da Inconfidência, p. 97-100. 
silábica do poema, reforçando o caráter subversivo dessas ideias. O que chama atenção nesse poema, bem como em outros que compõem a obra, é a forma como este se reporta aos medos e à violência nas suas mais diversas formas, como se pode observar nos versos abaixo:

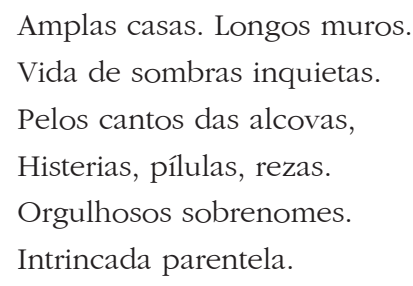

Em versos marcados pela ausência de verbos, o que parece querer apontar para a incapacidade dessas mulheres de ter livre arbítrio e agir, a vOZ poética descreve de forma concisa o cotidiano de mulheres restritas ao espaço da casa. A questão da honra familiar ("orgulhosos sobrenomes") e a impossibilidade de vivenciar seus sentimentos provocam a presença de "sombras inquietas", cuja única alternativa é calar seus sentimentos através de rezas, pílulas, sonhos ou prantos escondidos, como se pode perceber em outros poemas. Atitudes que, por não se adequarem ao comportamento que se espera das donzelas / senhoras da época, surgem como espaços de resistência. É interessante observar o contraste que se estabelece entre a amplitude das casas e o tamanho dos muros e a presença feminina nos cantos das alcovas - imagem que reforça a ideia do isolamento e solidão vivenciados por essas mulheres. Para realçar essa atmosfera de opressão, os adjetivos são antepostos aos substantivos.

O Romanceiro, no entanto, não se restringe ao desnudamento das relações entre os membros da elite da época. Muito pelo contrário, a obra se refere igualmente às pessoas marginalizadas física e simbolicamente do espaço da nação, como os "leprosos e encarangados", 27 bem como os povos escravizados vindos de África que, embora fossem a base da economia da época, encontramse quase ausentes das narrativas da nação. No "Romance XXII ou Das Idéias", a questão da escravidão é retratada nos seus mais diversos aspectos como na referência à figura da mãe preta ou da mulata reduzida ao papel de "objeto de

27. MEIRELES. Romanceiro da Inconfidência, p. 200. 
prazer" do seu senhor, como se pode ver nos seguintes versos: "No batuque das mulatas, / a prosápia degenera [...] Negras de peitos robustos / que os claros meninos cevam". Nesse caso, é interessante observar a forma como o poema reproduz um imaginário que delimita os papéis a serem ocupados pelas mulheres: o uso do termo "mulata" ligado à esfera do prazer, "negra" associado à esfera do trabalho e "donzela/dona" ligados ao espaço da casa e regido pelo código de honra. O uso destes termos ajuda a desnudar a natureza complexa e multidimensional do poder, desvendando a faceta opressiva dos encontros diários e desafiando a noção de um povo pacífico e homogêneo apregoado por discursos nacionalistas.

Em outros momentos, depara-se o leitor com a presença de versos que, constituídos por substantivos simples, procuram apreender de forma seca e direta uma realidade na sua diversidade e crueldade. $O$ uso de pontos para separar os substantivos impede a fluidez da leitura, uma estratégia que parece querer forçar o leitor a refletir sobre cada um desses termos:

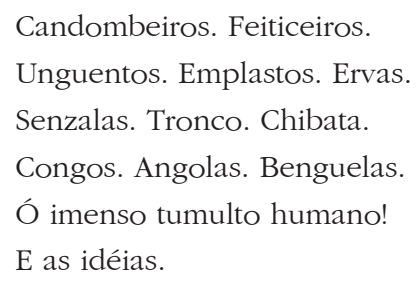

Como se pode verificar, os versos recuperam uma memória que interliga referenciais religiosos ao conhecimento medicinal dos africanos. O verso "Congos. Angolas. Benguelas.", por sua vez, é constituído de três substantivos que resumem de forma sucinta os principais aspectos do período de escravidão dos africanos e de seus descendentes no Brasil. O verso seguinte se reporta aos locais de onde foram capturados os africanos trazidos para o Brasil. Nesse caso, o uso do plural recupera uma diversidade usualmente ausente nos relatos oficiais. A referência à presença de escravos, negros e mulatas, no entanto, não fica restrita a esse poema ou a outros poemas que estão relacionados especificamente à vida de Chico Rei ou de Chica da Silva. Ao longo da obra, aparecem continuamente versos que atestam a presença dos escravos, negros e mulatas, que são arrolados como parte integrante da sociedade da época, como 
na cena do enforcamento do Alferes, "Romance LX ou do caminho da forca", em que, em meio à multidão, encontram-se: "os meninos e os ciganos, / as mulatas e os escravos, / os cirurgiões e algebristas".

O desejo de deslocar a história oficial, no entanto, não se limita à inclusão de novos atores sociais. No "Romance XXI ou das Idéias", o resgate de um quotidiano marcado por doenças, ferimentos e partos ajuda a romper com uma percepção de nação construída a partir de histórias de grandezas, de vitórias e de sacrifícios pela pátria:

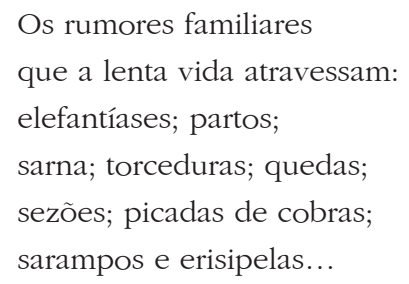

É interessante observar que quase todos os substantivos vêm no plural e que a listagem fica em aberto, pois termina por reticências, sugerindo a existência de outros elementos que poderiam ser acrescidos a essa lista. Um ponto que chama a atenção é que, ao colocar lado a lado no primeiro verso do inventário "elefantíases" e "partos", a voz poética justapõe termos que metonimicamente ilustram o processo de construção da memória. Para ser mais específica, ao colocar como primeiro termo da listagem "elefantíases”, a voz poética se reporta a um tipo de doença que, mesmo nos nossos dias, estigmatiza seus portadores, que se sentem (e são) alijados da sociedade. Essa justaposição, portanto, aponta para a presença de realidades que são excluídas do conceito de nação imaginada, desenhando uma realidade mais complexa e com a qual o leitor pode finalmente se identificar.

As duas últimas estrofes do "Romance XXI ou das Idéias" retomam a questão da inconfidência, ao fazer alusão ao exemplo americano, ao ouro, à ameaça de novos impostos, à poesia árcade e aos sonhos de um novo mundo. O poema termina com a repetição da conjunção aditiva "e", que retoma o clima de cobiça e traição:

28. MEIRELES. Romanceiro da Inconfidência, p. 200-203.. 


\begin{abstract}
E os inimigos atentos, que, de olhos sinistros, velam.

$\mathrm{E}$ os aleives. E as denúncias.

$\mathrm{E}$ as idéias.
\end{abstract}

Nesse caso, é importante observar como a última estrofe procura contrapor sonho e realidade, poesia e fatos, numa inflexão que se esforça por recuperar a faceta trágica e violenta da vida em Vila Rica, como se pode ver nos versos abaixo:

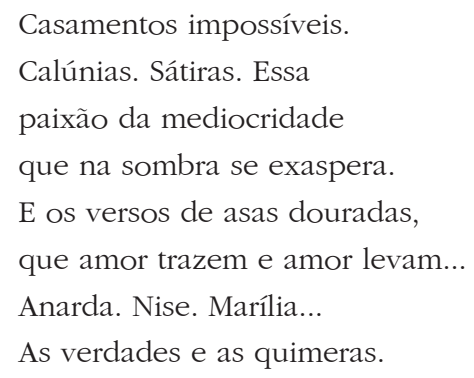

Se, como adverte Maurice Halbwachs, as memórias só podem ser rememoradas e localizadas quando "elas são parte de uma totalidade de pensamentos comuns a um grupo", não causa surpresa a forma como o Romanceiro procura entrelaçar a experiência de indivíduos comuns à da nação. ${ }^{29}$ Sem sombra de dúvida, ao privilegiar uma forma de escrita que se estrutura, entre outras estratégias, a partir de inventários que lidam com aspectos do quotidiano e com pessoas comuns, o Romanceiro questiona o próprio processo de institucionalização da história. A ironia maior reside no fato de esses inventários serem constituídos a partir de uma linguagem que se quer neutra e objetiva, mas que remete o leitor a uma nação no que esta possui de múltiplo, de absurdo e de contraditório.

O viés de educadora de Cecília Meireles nos ajuda a compreender a necessidade de construir esses novos contornos para a nação. Como alerta Roland Barthes, os artefatos culturais têm um papel chave na transmissão de mitos que procuram delimitar, definir, normalizar e naturalizar significados que

29. HALBWACHS. On collective memory, p. 52. 
têm sido erroneamente percebidos como algo neutro e inocente. É precisamente essa relação entre cultura/conhecimento e poder, presente no ato de contar e recontar histórias, que o Romanceiro procura desnudar, recusando-se a participar do canto "harmonioso" da nação. Pode-se dizer, então, que, consciente do papel de relevo da cultura no processo de socialização e formação dos jovens cidadãos, o inventário arrolado pela meirinha Cecília Meireles visa interrogar o tempo presente em que discursos nacionalistas não implicam uma real democracia, desvestindo a nação de sua capa mítica. Os versos que compõem a epígrafe e que falam da necessidade dos sonhos, por outro lado, nos remetem a uma carta escrita para Fernando de Azevedo em 1933. Na missiva, desiludida com a falta de continuidade na luta pela modernização do ensino por parte dos próprios adeptos da Escola Nova, Cecília afirma: "Não sei como se possa viver sem um sonho grande, e sem a disposição heroica de o servir". ${ }^{30}$ O Romanceiro da Inconfidência faz o mesmo questionamento em sua construção de uma nova ficção do passado, em que transparece de forma clara a "farpa" que, nascida dos confrontos dos anos 30, como tão bem adverte Valéria Lamego, tem sido muitas vezes esquecida na leitura de sua poesia. Pode-se dizer assim que, apesar do tom mais desiludido presente em suas crônicas nos anos 40, Cecília Meireles não esmoreceu em seu propósito de articular uma visão crítica, como se pode perceber na forma como seus versos recuperam e interferem no modo como se registra a história oficial.

\title{
Romanceiro da Inconfidência: the construction of a biography in falsetto
}

\begin{abstract}
The present essay intends to examine some of the inventories in Romanceiro da Inconfidência in order to discuss the way these elements contribute to the production of a catalogue that problematizes both a politics of identity and the construction of the nation.
\end{abstract}

Keywords: Memory, History, Nation.

30. LAMego. A farpa na lira, p. 109. 


$$
\text { Referências }
$$

APPLE, Michael W. Teachers and texts: A political economy of class and gender relations in education. New York: Routledge \& Kegan Paul, 1986.

ANDERSON, Benedict. Imagined communities: Reflections on the origin and spread of nationalism. Revised Edition. London: Verso, 1991.

BARTHES, Roland. Mythologies. New York: Noonday Press, 1988.

BERNUCCI, Leopoldo M. That gentle epic: Writing and elegy in the heroic poetry of Cecília Meireles. MLN, Baltimore, v. 112, n. 2, p. 201-218, 1997.

CARVALHO, José Murilo de. A formação das almas: o imaginário da República no Brasil. São Paulo: Companhia das Letras, 1990.

CHAUÍ, Marilena. Brasil: mito fundador e sociedade autoritária. São Paulo: Fundação Perseu Abramo, 2000

DELEUZE, Gilles. Difference and repetition. Trans. Paul Patton. New York: Columbia University Press, 1994.

HALBWACHS, Maurice. On collective memory. Chicago: University of Chicago Press, 1992.

KIRMAYER, Lawrence J. Landscapes of memory: Trauma, narrative, and dissociation. In: ANTZE, Paul; LAMBEK, Michael. Tense past: Cultural essays in trauma and memory. New York: Routledge, 1996. p. 173-198.

LAMEGO, Valéria. A farpa na lira: Cecília Meireles na Revolução de 30. Rio de Janeiro: Record, 1996.

LOBO, Yolanda Lima. Memória e educação: o espírito victorioso de Cecília Meireles. Revista Brasileira de Estudos Pedagógicos, Rio de Janeiro, v. 77, n. 187, p. 525-545, 1996.

MAXWELL, Kenneth. Conflicts and conspiracies: Brazil and Portugal, 1750-1808. Cambridge: Cambridge UP, 1973.

MEIRELES, Cecília. Romanceiro da Inconfidência. 7 ed. Rio de Janeiro: Nova Fronteira, 1994.

MOREIRA, Luiza Franco. Cecília Meireles' contribuitions to A Manhã. 1st Conference of Brazilian Women Writers. New York. 15 out. 2009.

NISKIER, Arnaldo. Cecília Meireles: a educadora. Disponível em: <http://academia.org. br/abl/media/prosa5.pdf>. Acesso em: 23 fev. 2009.

OLICK, Jeffrey K. What does it mean to normalize the past? Official memory in German politics since 1989. Social Science History, Beverly Hills, v. 22, n. 4, p. 547-571, 1998.

WILLIAMS, Raymond. Hegemony and the selective tradition. In: CASTELL, Suzanne de; LUKE, Allan; LUKE, Carmen (Ed.). Language, authority and criticism: Readings on the school textbook. London: The Falmer Press, 1989. p. 56-60.

YUVAL-DAVIS, Nira; ANTHIAS, Floya. Introduction. In: YUVAL-DAVIS, Nira; ANTHIAS, Floya; CAMPLING, Jo (Ed.). Women-nation-state. Basingstoke: Macmillan, 1989. p. 1-15. 